\title{
Phytochemical analysis and cytotoxicity evaluation of flowering buds of Bauhinia variegata $\mathrm{L}$.
}

\author{
ANHAM SHAHID ABBASI ${ }^{1}$, QAZI NAJAM-US-SAQIB ${ }^{2} \odot$, ATTA-UR-REHMAN ${ }^{1 *} \odot$, \\ NISAR-UR-RAHMAN ${ }^{1 \odot}$
}

\author{
${ }^{1}$ Margalla College of Pharmacy \\ Margalla Institute of Health Sciences \\ Rawalpindi, Pakistan \\ ${ }^{2}$ Department of Pharmacy \\ Comsats Institute of Information Technology \\ Abbottabad, Pakistan \\ *corresponding author: phone: 03009104 733; e-mail: attaurrehman1987@yahoo.com
}

\section{Summary}

Introduction: Bauhinia variegata is used in traditional medicine in Pakistan.

Objective: The present study was designated to analyze phytochemical screening and cytotoxicity assay of crude aqueous and methanol extracts of flowering buds of Bauhinia variegata.

Methods: Qualitative and quantitative phytochemical screening of both extracts were performed by using standard protocols while brine shrimp lethality assay was conducted for cytotoxicity analysis of both extracts.

Results: The highest levels of phenolics, flavonoids and terpenoids were observed in methanol extract with respective standard drugs. The aminoacid content was highest followed by phenol and flavonoids in crude aqueous extract of the raw materials. In cytotoxic studies (brine shrimp lethality assay) the use of methanol extract was reported as potent with $\mathrm{LD}_{50}$ of $241.778 \mu \mathrm{g} / \mathrm{ml}$ as compared to aqueous extract with $\mathrm{LD}_{50}$ of $489.7061 \mu \mathrm{g} / \mathrm{ml}$.

Conclusion: This study reveals that the presence of bioactive compounds in both extracts are responsible for the treatment of various ailments and being utilized by the traditional folks as a food as well. And showed that methanol extract possess cytotoxic activity and thus needs further scientific intervention for its value addition. 


\title{
Key words: Bauhinia variegata, phytochemical analysis, cytotoxic activity, secondary metabolites
}

\author{
Słowa kluczowe: Bauhinia variegata, analiza fitochemiczna, działanie cytotoksyczne, metabolity \\ wtórne
}

\section{INTRODUCTION}

The ethnobotanical importance of plants is as old as mankind. In pre-historic societies, plant medicines were found everywhere, whereas 7,000 conventional medicines such as aspirin, digoxin, morphine, quinine, etc. have been obtained from plants and have been included in the modern pharmacopeia. A review from 1981 to 2007, showed that since 1994 majority of the drugs (35\%) approved by the FDA are derived from natural sources. Researchers have made many attempts to explore many secondary metabolites (flavonoids, alkaloids, saponin, tannins, phenols, carbohydrates, phenolic glycosides, cyanogen glycosides) with pharmacological and biological activities against cancer, diabetes, ulcers, and many other diseases. Keeping in view the importance of natural drugs pharmaceutical industries are anxious about the knowledge of indigenous people regarding the uses of herbs to search for new active secondary metabolites $[1,2]$.

The Fabaceae family covers the Bauhinia genus. This family comprises of 630 genera and 18,000 species. The plants included in this family are deciduous trees, shrubs, vines, and are well known for ornamental purposes. Bauhinia is a famous plant called by various names, like Kachnar in Hindi, Raktakanchan in Marathi; English users named it as an orchid tree as well as Mountain ebony. The Kachnar word means "A glowing beautiful lady" in transcripts of Sanskrit [3]. It is widely planted in many native countries like India, South China, Pakistan, Burma, Vietnam, Cambodia, Laos, and Thailand [4]. In native countries, flowers, buds, pods, and seeds of Kachnar are cooked and used to make pickle [5]. Different plant parts are used for medicinal purposes in South Asia in Unani, Ayurveda, and homeopathic health belief models. The plant parts that are most frequently used are flowers, stem, buds, stem bark, leaves, roots, and seeds [6].

The antidiabetic activity of stem bark and leaves of $B$. variegata was discovered in rats using hydroalcohol, ethanol, and aqueous extracts. The metabolism of glucose in rats was increased with oral extract administration of various strengths that resulted in the reduction of raised glucose levels in blood. Further experimental work established that leaves of $B$. variegata contained insulin-similar proteins that stimulate the metabolism of glucose $[7,8]$. The preparation of leaves in an ethanolic extract at a dose of $300 \mathrm{mg} / \mathrm{kg}$ was related to the decrease of blood glucose levels and enhanced lipid profile. The results of in vitro study emphasized that $B$. variegata and roesoside leaves extracts in ethanol could upsurge the insulin release in the INS- $1 \beta$-cell line. The decrease in blood glucose levels in alloxan-induced rats was also proposed on regeneration of $\beta$-cells with the use of ethanolic bark extract, ranging from 250 to $500 \mathrm{mg} / \mathrm{kg}$ $[9,10]$. The presence of flavonoid rhamnocitrin in B. variegata stem bark confirmed the anti-cataract potential of the plant. The anti-cancerous effect of B. variegata ethanolic stem extract was experimentally determined on Swiss Albino mice. The cell line growth of cancer against Dalton's ascetic lymphoma was inhibited by stem. The effect was also estimated by using the same extract against Ehrlich ascites carcinoma. The stem extract showed antimutagenic activity. The orally given ethanol extract successfully decreases $\mathrm{N}$-nitrosodiethylamine enhanced enzymes [11].

B. variegata flowering buds contain amino acids of four types in early stages. They are glutamic acid, aspartic acid, glycine, and $\alpha$-alanine. The mature stages of buds contain $\alpha$-keto glutaric acid, oxaloacetic acid, and phosphoenolpyruvic acid. In folkloric medicinal system, the flowering buds of $B$. variegata were used to treat hemorrhoids, dysentery, and diarrhoea. The flowers of B. variegata were used to treat oedema and dysentery and as a laxative and anthelmintic agent. The floral bud and flowers were ingested frequently for mumps and leucorrhoea treatment. B. variegata flowering buds in Unani medicine system were used for cough treatment, ophthalmic infections, liver complications, and hematuria menorrhagia $[12,13]$.

The presence of $B$. variegata in Pakistani flora with traditional usage and established pharmacological activities from investigations evoked to explore the phytochemical analysis and cytotoxicity evaluation of flowering buds of B. variegata [14]. This investigation was planned to estimate preliminary phytochemical analysis, with purpose to determine the 
secondary metabolites that may be associated with the cytotoxic activity of flowering buds of $B$. variegata $[15,16]$.

\section{MATERIAL AND METHODS}

\section{Plant collection}

Bauhinia variegata was procured from Faislabad for experimental purposes. The expert botanist Prof. Dr. Qazi Najam us Saqib from Pharmacy Department, Abbottabad University, Pakistan, identified and authenticated the plant. One portion of sample was placed in a local herbarium and served as a reference. The flowering buds were used as a plant part. The plant part was shade dried at a room temperature. After adequate drying, the plant material was then chopped to a fine powder. The powdered material was weighed properly and stored in a tight polyethene bag for further study $[17,18]$.

\section{Extract preparation}

The extraction flask was used for soaking $200 \mathrm{~g}$ of dried powder of $B$. variegata flowering buds in 1 liter of menthol-water solution $(70-30 \% v / v)$. The herbal mixture was kept in the darkroom for 14 days. Daily shaking of the mixture was done twice during this period. After 14 days, filtration was carried out with Whatman filter paper No. 1. The methanolic extract and residues were separated. The residues were added in $300 \mathrm{ml}$ of methanol and the same process was adopted thrice. The rotary evaporator was used for drying filtrate at $40^{\circ} \mathrm{C}$. The same procedure was performed using plant material and water as a solvent to get aqueous extract respectively [19].

\section{Chemicals and reagent solutions}

Analytical grade pure chemicals and reagent solutions procured from E. Merck Germany was used in the investigation (E.Merck, Germany).

\section{Phytochemical analysis}

Qualitative phytochemical analysis of both extracts B. variegata flowering buds were performed by following standard procedures for screening secondary metabolites such as saponins, flavonoids, carbohydrates, proteins, phenols, terpenoids, glycosides, alkaloids, tannins in respective plant [3].

\section{Alkaloid test}

0.2 gram of crude aqueous and methanol extract of $B$. variegata flowering buds were treated with dilute $\mathrm{HCl}$ to make acidic mixture. The reaction mixture was filtered and treated with few drops of reagents one by one and observed for any change in color. Hyoscine was used as a standard. All the reagents were freshly prepared in accordance with the reference.

1. Mayer's reagent

2. Wagner's reagent

3. Dragendroff's reagent

\section{Carbohydrates test}

0.2 gram of crude aqueous and methanol extract of $B$. variegata flowering buds were treated with different reagents to detect the presence or absence of carbohydrates. Glucose was used as a standard.

a) Fehling's reagent

Fehling $\mathrm{A}$ and Fehling $\mathrm{B}$ reagents were mixed in equal volume and $2 \mathrm{ml}$ of this mixture was added to test sample and the changes in colour was observed.

b) Benedict's reagent

Added Benedict's reagent to the test tube containing sample and the changes in colour was observed.

\section{Test for flavonoids}

0.2 gram of crude aqueous and methanol extract of B. variegata flowering buds were treated with different reagents to detect the presence/absence of flavonoids. Tea leaves are used as a standard.

1. $4 \mathrm{ml}$ of $1 \% \mathrm{KOH}$ was added to filtrate in a test tube and the changes were observed.

2. $4 \mathrm{ml}$ of $1 \%$ already prepared $\mathrm{AlCl}_{3}$ in methanol was added to filtrate in a test tube and the changes were observed.

\section{Phenols test}

0.2 gram of crude aqueous and methanol extract of B. variegata flowering buds were taken in a test tube 
and few drops of $5 \%$ ferric chloride solution were added. The changes were observed. Olives were used as a reference.

\section{Saponins test}

0.2 gram of crude aqueous and methanol extract of B. variegata flowering buds were taken in a test tube and boiled for 3 minutes. It was filtered and cooled. The reaction mixture was treated with few drops of reagents one by one to detect the absence and presence of saponins. Glycyrrihza was used as a standard.

1. In a test tube extracts were taken and shaked for about 1 minute and then observed the appearance of froth formation.

2. In a test tube extracts were taken and lead acetate was added and then the changes were observed.

\section{Tannins test}

0.2 gram of crude aqueous and methanol extract of $B$. variegata flowering buds were treated with different reagents for the presence/absence of tannins. Tea leaves were used as a standard.

a) Vanillin test

Crude aqueous and methanol extract of B. variegata flowering buds were treated with vanillin reagent and the changes for the presence/absence of tannins were observed.

b) Gelatin test

Crude aqueous and methanol extract of B. variegata flowering buds were taken in a test tube and treated with $10 \%$ sodium chloride solution and $1 \%$ gelatin solution and the changes were observed.

c) Ferric chloride test

Crude aqueous and methanol extract of $B$. variegata flowering buds were treated with 5\% ferric chloride solution and the changes were observed.

\section{Glycosides test}

0.2 gram of crude aqueous and methanol extract of $B$. variegata flowering buds were treated with different reagents to detect the presence or absence of glycosides. Digitalis was used as a standard.

a) Modified Brontrager's test

Both aqueous and methanol extracts were added in a test tube along with dilute sulphuric acid. This solution was allowed to boil on a water bath for few minutes and then the mixture was filtered. The filtrate was allowed to cool and then 2-3 drops of benzene were added to the solution, vigorously shaken to mix well and allowed to stand for complete separation of two organic layers. The organic layer was collected and equal of ammonia solution was added. The changes were observed.

b) Legal's test

To the crude aqueous and methanol extract of B. variegata flowering buds few $\mathrm{ml}$ of pyridine and 3 drops of nitroprusside and one drop of $20 \%$ sodium hydroxide solution was added and observed the changes.

\section{Proteins and amino acids test}

0.2 gram of crude aqueous and methanol extract of B. variegata flowering buds were treated with different reagents to detect the absence or presence of proteins and amino acids.

a) Xanthoproteic acid test

To the test tube of crude aqueous extract and methanol extract of $B$. variegata flowering buds few drops of concentrated nitric acid were added and changes were observed.

b) Ninhydrin test

$0.25 \% v / v$ ninhydrin reagent was added to the crude aqueous and methanol extract of $B$. variegata flowering buds in a test tube and boiled for a few minutes and then the changes were observed.

\section{Phytosterols test}

0.2 gram of crude aqueous and methanol extract of $B$. variegata flowering buds were treated with different reagents for the detection of phytosterols. Grapes were used as a standard.

a) Salkowski's test

The crude aqueous and methanol extract of B. variegata flowering buds were taken in a test tube with chloroform added. The mixture was filtered and filtrate was treated with a few drops of $\mathrm{H}_{2} \mathrm{SO}_{4}$ (conc) and allowed to stand for few minutes and then the changes were observed.

b) Libermann Burchard test

The crude aqueous and methanol extracts of B. variegata flowering buds were taken in a test tube with chloroform added. Filtered mixture and filtrate was treated with a few drops of $\mathrm{H}_{2} \mathrm{SO}_{4}$ (conc) was allowed to stand for a few minutes and the changes were observed. Mushroom was used as a standard. 


\section{Terpenoids test}

0.2 gram of crude aqueous and methanol extract of $B$. variegata flowering buds were taken in a test tube and $10 \mathrm{ml}$ of methanol was added. The mixture was shaked well and filtered. Then, $2 \mathrm{ml}$ of chloroform was added in to filtrate, followed by addition of $3 \mathrm{ml}$ of $\mathrm{H}_{2} \mathrm{SO}_{4}$. Then the changes in color were observed.

\section{Estimation of amino acid}

Total content of amino acid was assayed by following the ninhydrin method described by Gayathri et al. [20]. To $0.5 \mathrm{ml}$ of both extracts, $4 \mathrm{ml}$ of distilled water was added then $1 \mathrm{ml}$ of ninhydrin reagent was added and mixed well. After that the mixture was boiled, the reaction mixture was left in the hot water bath for 15 minutes, and the allowed to cool. Then, ethanol in $1 \mathrm{ml}$ quantity was added to the reaction mixture and mixed well. The absorbance was measured at $570 \mathrm{~nm}$ with the a calorimeter. The $100 \mu \mathrm{g} / \mathrm{ml}$ of glycine was assessed in the same way. The amounts of amino acids in flowering buds were expressed as $\mathrm{mg} / \mathrm{g}$ of flowering buds.

\section{Estimation of proteins}

Plant material was investigated for total protein contents following the method described by Gayathri et al. [20]. To $0.4 \mathrm{ml}$ of both extracts, $9 \mathrm{ml}$ distilled water wasa added in order to increase the volume and allowed to stand for some time, before the addition of $1.0 \mathrm{ml}$ of Folins-Ciocalteu reagent. The resultant mixture was shaken well before incubation at a room temperature. After five minutes, $10 \mathrm{ml}$ of $7 \%$ sodium carbonates solution was added to resultant mixture.The mixture was incubated again at $23^{\circ} \mathrm{C}$ for 90 minutes.After incubation, the calorimeter was used to measure the absorbance at $750 \mathrm{~nm}$. $100 \mu \mathrm{g} / \mathrm{ml}$ of gallic acid as a standard was assessed in the same way. The amounts of phenols in flowering buds were expressed as milligram of GAE/g of flowering buds.

\section{Estimation of flavonoids}

Total flavonoid contents were accessed with same procedure as adopted by Gayathri et al. [20]. To $0.5 \mathrm{ml}$ of both extracts, aluminum chloride $(10 \%)$ and sodium acetate $(0.1 \mathrm{M})$ were added. Distilled water in amount of $5.3 \mathrm{ml}$ was added to resultant mixture and then incubated for 30 minutes at a room temperature.Calorimeter was used to measure the absorbance at $420 \mathrm{~nm}$. The $100 \mu \mathrm{g} / \mathrm{ml}$ of quercertin used as a standard was assessed in the same way. The amount of flavonoids in flowering buds were expressed as milligram of QE/g of flowering buds.

\section{Cytotoxic evaluation}

The Brine shrimp lethality of each extract was conducted to determine the cytotoxicity following standard protocol by Atta-ur-Rehman et al. [21].

\section{Requirements}

Brine shrimp's eggs (eggs of Artemia salina), distilled water ( $\mathrm{pH} 7.4)$, sea salt $(3.8 \mathrm{~g} / \mathrm{l})$, aluminum foil, vials, micro pipette, hatching tray and ethanol.

\section{Sample preparation}

The $20 \mathrm{mg}$ of B. variegata flowering buds crude aqueous and methanol extracts were dissolved in $2 \mathrm{ml}$ of distilled water and dimethyl sulfoxide (DMSO) which served as a stock solution. Concertations of five diverse strengths of 500, 250, 125, 50, $25 \mu \mathrm{g} / \mathrm{ml} \mathrm{ppm}$ were transported into the vials (5 vials/concentration) from the stock solution. Evaporation of vial solvents was carried out and the residue was resolubilized in $2 \mathrm{ml}$ of sea water. The Pasteur pipette was used to place 10 larvae/vial. Seawater was used to makeup final volume up to $5 \mathrm{ml}$ with $100 \mathrm{ppm}, 125 \mathrm{ppm}, 225 \mathrm{ppm}, 500 \mathrm{ppm}$, $1000 \mathrm{ppm}$ of final concentrations and incubated at $250-270^{\circ} \mathrm{C}$ for 24 hours under light. The negative control vials have dimethyl sulfoxide and positive control vial has reference cytotoxic drug. The magnifying glass was used to count the survivors after 24 hours.

\section{Hatching the shrimp}

The perforated partition assisted in an unequal division of the hatching tray. The sprinkling of eggs was carried out in minor quantity over the solution (3.8 $\mathrm{g}$ of sea salt $+1000 \mathrm{ml}$ of distilled water). Aluminum foil was used to cover the solution for darkness. The tray was placed under the lamp when the eggs hatched out the larvae swam energetically and traveled to the illuminated area of the tray. 


\section{Statistical analysis}

Biostat software was used to calaculate $\mathrm{LD}_{50}$ values by probit analysis [22].

Ethical approval: The conducted research is not related to either human or animal use.

\section{RESULTS}

\section{Phytochemical analysis}

The phytochemical analysis of both extracts of flowering buds of $B$. variegata showed the existence of a variety of significant secondary metabolites like flavonoids, proteins, amino acids, terpenoids, etc. presented in table 1. While saponins and alkaloids were absent in both extracts. The highest levels of phenolics, flavonoids, and terpenoids were observed in methanol extract with the respective standard drugs. This can be attributable to the higher solubility of these compounds in methanol than in the aqueous medium.

Table 1.

Phytochemical analysis of crude aqueous and methanol extract of flowering buds of Bauhinia variegata

\begin{tabular}{ccc}
\hline \multirow{2}{*}{ Secondary metabolites } & \multicolumn{2}{c}{ Extracts } \\
\cline { 2 - 3 } & $\begin{array}{c}\text { Crude aqueous } \\
\text { extract }\end{array}$ & Methanol \\
extract
\end{tabular}

Alkaloids

a) Mayer's test
b) Dragendroff's test

Carbohydrates

a) Fehling's test $\quad++\quad++$

b) Benedict's test

\begin{tabular}{lcc}
\hline Flavonoids & ++ & ++ \\
\hline Phenols & ++ & ++ \\
\hline Saponins & -- & -- \\
\hline Tannins & + & + \\
\hline Glycosides & + & + \\
\hline
\end{tabular}

\section{Proteins}

a) Ninhydrin test $\quad++$
b) Xanthoproteic acid test

Phytosterols

\begin{tabular}{lll} 
a) Salkowski's test & + & + \\
b) Libermann Burchard test & & + \\
\hline Triterpenoids & + & + \\
\hline + present; - absent & &
\end{tabular}

\section{Quantitaive analysis of phytochemicals}

The quantitative analysis of both extracts of flowering buds of $B$. variegata was presented in table 2 . The aminoacid content was highest followed by phenol and flavonoids.

Table 2.

Quntitaive analysis of phytochemicals

\begin{tabular}{lll}
\hline \multicolumn{1}{c}{ Phytochemical } & BVM & BVA \\
\hline Total flavonoids $[\mathrm{mg} / \mathrm{QE} / \mathrm{g}]$ & $1.26 \pm 0.06$ & $4.26 \pm 0.26$ \\
\hline Total phenols $[\mathrm{mg} / \mathrm{GAE} / \mathrm{g}]$ & $3.96 \pm 0.09$ & $4.74 \pm 0.97$ \\
\hline Total amino acid $[\mathrm{mg} / \mathrm{Gly} / \mathrm{g}]$ & $7.71 \pm 9.8$ & $9.47 \pm 23.74$ \\
\hline
\end{tabular}

BVM - Bauhinia variegata methanol extract

BVA - Bauhinia variegata aqueous extract

\section{Quantitaive analysis of flavonoids}

The results of the quantitative analysis indicated that the content of flavonoids was higher in the aqueous extract compared with the methanol extract. The antioxidant activity and metal chelation potential of flavonoids are well recognized for herbal medicine prospective [23]. B. variegata is used in herbal theraphy for anti-inflammatory actions and hypoglycemic effects. The probit analysis of flavonoids are presented in figure 1.

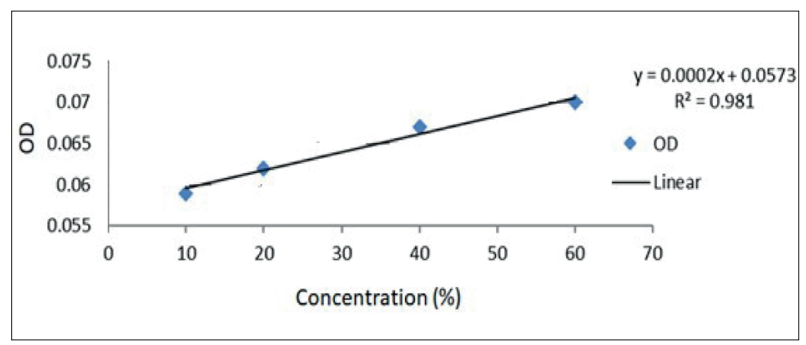

OD - optical density

Figure 1.

Total flavonoid content (mg/QE/g) of Bauhinia variegata flowering buds

\section{Quantitaive analysis of phenols}

The results of the quantitative analysis of phenols showed that the content of phenol was higher in aqueous extract compared with methanol extract. The rich phenolic content used in food products minimizes heart disease due to antioxidant potential as well as effectiveness in chemotherapy and osteoporosis treatment [24]. The probit analysis of phenols were presented in figure 2 . 


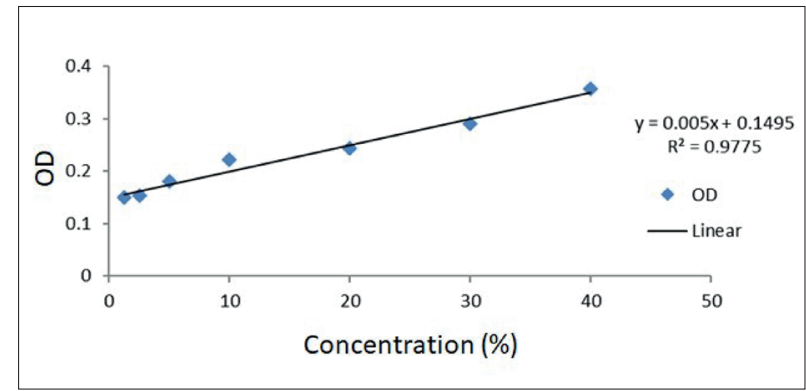

OD - optical density

Figure 2.

Total phenol content (mg/GAE /g) of Bauhinia variegata flowering buds

\section{Quntitaive analysis of amino acids}

The results showed that aqueous extract $(9.74 \pm 23.74 \mathrm{mg} / \mathrm{g})$ contains higher amount of amino acids compared to methanol extract $(7.71 \pm 9.8 \mathrm{mg} / \mathrm{g})$. The human body needs protein in adequate amounts for development and as a structural constituent of body cells. Proteins act as precursors for vital molecules for lifespan. The analysis of flowering buds of $B$. variegata at early stages resulted in glutamic acid, aspartic acid, glycine, and $\alpha$-alanine. The mature stages of buds contain $\alpha$-ketoglutaric acid, oxaloacetic acid, and phosphoenolpyruvic acid. B. variegata has enriched nutrition value with amino acids and protein content and also served as a source of energy during malnourishment. The probit analysis of amino acids was presented in figure 3 .

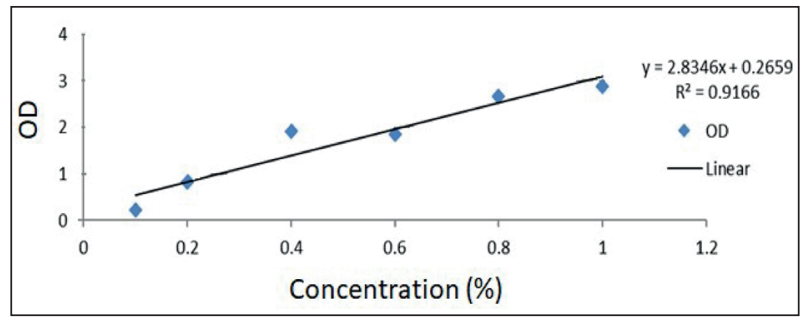

OD - optical density

Figure 3.

Total amino acid content (mg/Gly/g) of Bauhinia variegata flowering buds

\section{Cytotoxic evaluation}

The brine shrimp lethality assay was introduced by Michael et al. and further studied by Vanhaecke et al. and Sleet and Brendel [25-27]. The lethality of the test sample was based on the concept to kill laboratory cultured Artemia nauplii (brine shrimp) larvae have been used by researchers, considered as a beneficial tool for preliminary assessment of toxicity that can be backed up by more specific bioassay [28] The probit analysis of crude aqueous extract and methanol extract are presented in figure 4 .

In this study, lethality was found to be directly proportional to the concentration of extracts ranging from the lowest $(100 \mu \mathrm{g} / \mathrm{ml})$ to the highest $(1000 \mu \mathrm{g} / \mathrm{ml})$. This concentration-dependent increased death rate of Artemia showed the presence of cytotoxic active principles present in

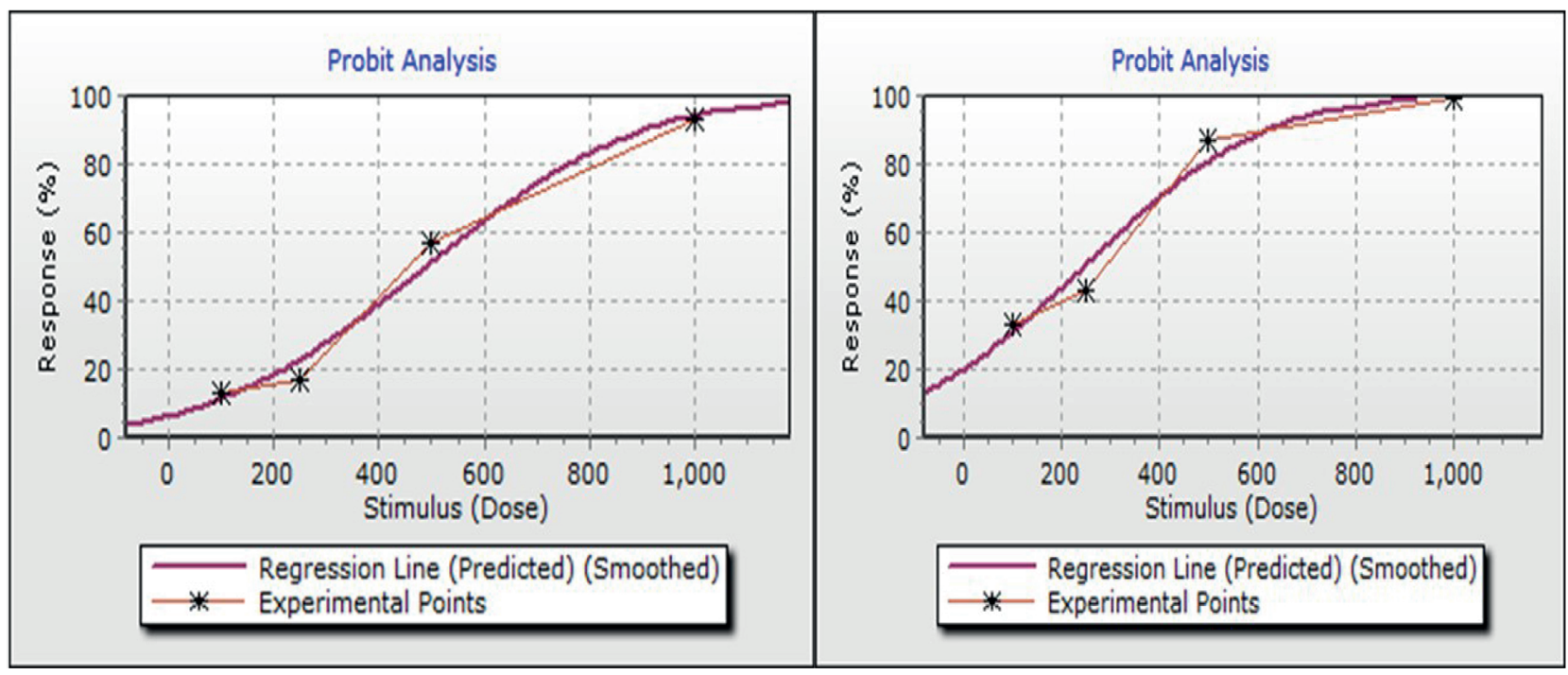

Figure 4.

Cytotoxic activity of aqueous and methanol extracts of Bauhinia variagata flowering buds 
extracts. The results of this activity showed that methanol extract is more toxic than crude aqueous extract with $\mathrm{LD}_{50} 241.778 \mu \mathrm{g} / \mathrm{ml}$ with the upper and lower confidence interval of $315.78 \mu \mathrm{g} / \mathrm{ml}$, $174.98 \mu \mathrm{g} / \mathrm{ml}$ and $489.7061 \mu \mathrm{g} / \mathrm{ml}$ with upper and lower confidence interval of $653.5212 \mu \mathrm{g} / \mathrm{ml}$ and $352.890 \mu \mathrm{g} / \mathrm{ml}$, respectively. The results are presented in table 3.

\section{Table3.}

Cytotoxicity results of crude aqueous extract and methanol extract of flowering buds of Bauhinia variegata

\begin{tabular}{ccccc}
\hline \multicolumn{5}{c}{ Cytotoxicity results of crude aqueous extract } \\
\hline $\begin{array}{c}\text { Dose } \\
{[\mu \mathrm{g} / \mathrm{ml}]}\end{array}$ & Log dose & $\begin{array}{c}\text { Total } \\
\text { No. of } \\
\text { shrimps }\end{array}$ & $\begin{array}{c}\text { No. of } \\
\text { dead } \\
\text { shrimps }\end{array}$ & Probit \\
\hline 1000 & 3.000 & 30 & 28 & 7.9394 \\
\hline 500 & 2.699 & 30 & 17 & 6.1108 \\
\hline 250 & 2.3979 & 30 & 5 & 4.8324 \\
\hline 100 & 2.097 & 30 & 4 & 4.5697 \\
\hline \multicolumn{5}{c}{ Cytotoxicity results of methanol extract } \\
\hline 1000 & 3.000 & 30 & 30 & 7.9394 \\
\hline 500 & 2.699 & 30 & 26 & 6.1108 \\
\hline 250 & 2.3979 & 30 & 13 & 4.8324 \\
\hline 100 & 2.097 & 30 & 10 & 4.5697 \\
\hline \multicolumn{5}{c}{} \\
\hline
\end{tabular}

\section{DISCUSSION}

B. variegata flowering buds are used as a vegetable in most of areas of Indo-Pak but it is unfortunate that after boiling with water, water is thrown away which causes loss of some essential macro- and microelements. This genus attained great pharmaceutical and industrial interest because of the presence of polyphenols and flavonoids i.e. kaempferol and ombuin. The isolated compounds from this genus possess anti-inflammatory, anti-oxidant, anti-diabetic, immunomodulatory activity etc. Others are anthraquinones, according to the Unani system of medicine. The flowering buds of $B$. variegata enriched with anthraquinones are used in the treatment of cough, eye disease, liver complaints and as styptic in heamaturia menorrhagia [16]. The brine shrimp lethality assay represents fast, cheap and simple bioassay for testing plant extracts bioactivity which in most cases correlates with the presence of flavonoids in this plant. This is an indicative of presence of potent cytotoxic compounds which warrants further studies.

\section{CONCLUSION}

From the above studies, it can be concluded that the plant $B$. variegata flowering buds possess many secondary metabolites proteins, flavonoids, terpenes, anthraquinones, terpenoids and can be incorporated for treatment of various ailments as folklore medicine such as dried buds are employed in the treatment of dysentery, diarrhea, infestation, worms, tumors, and piles. However, it provides a validation of the cytotoxic effect of the plant extracts which might indicate baseline information in understanding the possible medicinal value, and further clinical studies are needed.

\section{Abbreviations}

$\mathrm{LD}_{50}$ - median lethal dose

FDA - Food and Drug Administration

Conflict of interest: Authors declare no conflict of interest.

\section{REFERENCES}

1. Talukdar AD, Tarafdar RG, Choudhury MD, Nath D, Choudhury S. A review on pteridophyte antioxidants and their potential role in discovery of new drugs. Assam Univ J Sci Technol 2011; 7(1):151-155.

2. Farias DF, Souza TM, Viana MP, Soares BM, Cunha AP, Vasconcelos IM, et al. Antibacterial, antioxidant, and anticholinesterase activities of plant seed extracts from Brazilian Semiarid region. BioMed Res Int 2013:510736. https://doi. org/10.1155/2013/510736

3. Patil J, Patel M, Sayyed H, Patel A, Pokal D, Suryawanshi $\mathrm{H}$, et al. Pharmacognostic and phytochemical investigation of Bauhinia variegata (Linn.) Benth. stem bark. Pharm Sci Monitor $2012 ; 3(1)$.

4. Sharma S, Kumar A. Tribal uses of medicinal plants of Rajashthan: Kachnar. Int J Life Sci Pharm Res 2012; 2(4):68-76.

5. Rajesh G, Paarakh P, Usha G. Isolation of phytoconstituents from the leaves of Bauhinia variegata Linn. J Pharm Res 2009; 2(8):1315-6. http:// jpronline.info/article/view/50/43 0974-6943 
6. Koti B, Biradar SM, Karadi R, Taranalli AD, Benade VS. Effect of Bauhinia variegata bark extract on blood glucose level in normal and alloxanised diabetic rats. J Nat Remed 2009; 9:27-34. http://www.jnronline.com

7. Rajkapoor B, Jayakar BRA, Kavimani S. Anti-ulcer effect of Bauhinia variegata Linn. in rats. J Nat Remed 2003; 3:215-7.

8. Azevedo CR, Maciel FM, Silva LB, Ferreira A, Cunha M, Machado O, et al. Isolation and intracellular localization of insulin-like proteins from leaves of Bauhinia variegata. Brazilian J Med Biol Res 2006; 39:1435-1444. doi: http://dx.doi. org/10.1590/S0100-879X2006001100007

9. Kumar P, Baraiya S, Gaidhani S, Gupta M, Wanjari MM. Antidiabetic activity of stem bark of Bauhinia variegata in alloxan-induced hyperglycemic rats. J Pharmacol Pharmacother 2012; 3(1):64. doi: http://dx.doi.org/10.4103/0976500X.92518

10. Bodakhe SH, Ram A, Verma S, Pandey DP. Anticataract activity of rhamnocitrin isolated from Bauhinia variegata stem bark. Oriental Pharm Experim Med 2012; 12(3):227-232. doi: https:// dx.doi.org/10.1007/s13596-012-0059-1

11. Kumar YR, Rajani GP. Analgesic and anti-ulcer activities of ethanol and aqueous extracts of root of Bauhinia variegata Linn. Intern J Pharmacol 2011; 7:616-622.

12. Rajkapoor B, Jayakar B, Murugesh N. Antitumour activity of Bauhinia variegata on Dalton's ascitic lymphoma. J Ethnopharmacol 2003; 89(1):107-109. doi: https://dx.doi.org/10.1016/ S0378-8741(03)00264-2

13. Rajkapoor B, Jayakar B, Murugesh N. Antitumour activity of Bauhinia variegata against Ehrlich ascites carcinoma-induced mice. Pharmac Biol 2003; 41(8):604-607. doi: https://dx.doi. org/10.1080/13880200390501947

14. Mukherjee D, Laloraya MM. Keto acids and free amino acids during leaf growth in Bauhinia purpurea L. Experientia 1977; 33(3):304-305. doi: https://dx.doi.org/10.1007/BF02002793

15. Frankish N, de Sousa Menezes F, Mills C, Sheridan $\mathrm{H}$. Enhancement of insulin release from the $\beta$-cell line INS- 1 by an ethanolic extract of
Bauhinia variegata and its major constituent roseoside. Planta Med 2010; 76(10): 995-997. doi: https://dx.doi.org/10.1055/s-0029-1240868

16. Badhe P, Pandey V. A study of medicinal and economic plants of Amravati division, Amravati circle, Maharashtra. Bull Med Ethnobot Res 1990;11:1-39.

17. Seidel V. Initial and bulk extraction of natural products isolation. Natural products isolation. Springer 2012:27-41. doi: https://dx.doi. org/10.1007/978-1-61779-624-1_2

18. Handa SS, Khanuja S, Longo G, Rakesh DD. An overview of extraction techniques for medicinal and aromatic plants. Extract Technol Med Arom Plants 2008:21-52.

19. Pandey S, Agrawal R, Maheshwari S. In-vitro antioxidant and free radical scavenging activity of Bauhinia variegata Linn. Intern J Sci Res Publ 2012; 2(2):1-5.

20. Gunalan G, Saraswathy A, Vijayalakshmi K. Quantitative phytochemical profile of Bauhinia variegata Linn. leaves. Intern J Biol Pharmac Res 2013; 4(12):907-915.

21. Atta-ur-Rehman CM, Thomsen W. Bioassay technique for drug development. Harwood Academic Publishers 2001.

22. Barkatullah B, Ibrar M. Plants profile of Malakand Pass Hills, District Malakand, Pakistan. Afr J Biotechnol 2011; 10(73):16521-35. doi: https:// dx.doi.org/10.5897/AJB11.1258

23. Edeoga HO, Okwu D, Mbaebie B. Phytochemical constituents of some Nigerian medicinal plants. Afr J Biotechnol 2005; 4(7):685-688. doi: https:// dx.doi.org/10.5897/AJB2005.000-3127

24. Kanner J, Frankel E, Granit R, German B, Kinsella JE. Natural antioxidants in grapes and wines. J Agric Food Chem 1994; 42(1):64-69. doi: https:// dx.doi.org/10.1021/jf00037a010

25. Michael A, Thompson C, Abramovitz M. Artemia salina as a test organism for bioassay. Science 1956; 123(3194):464. doi: https://dx.doi. org/10.1126/science.123.3194.464

26. Vanhaecke P, Persoone G, Claus C, Sorgeloos P. Proposal for a short-term toxicity 
test with Artemia nauplii. Ecotoxicol Environ Safety 1981; 5(3):382-387. doi https://dx.doi. org/10.1016/0147-6513(81)90012-9

27. Sleet R, Brendel K. Improved methods for harvesting and counting synchronous populations of Artemia nauplii for use in developmental toxicology. Ecotoxicol Environ Safety 1983; 7(5):435446. doi: https://dx.doi.org/10.1016/01476513(83)90082-9
28. Solis PN, Wright CW, Anderson MM, Gupta MP, Phillipson JD. A microwell cytotoxicity assay using Artemia salina (brine shrimp). Planta Med 1993; 59(3):250-252. doi: https://dx.doi. org/10.1186/1472-6750-2-17 